\title{
Structure-property relationships in the R-type hexaferrites: Cation distributions and magnetic susceptibilities of $\mathrm{MX}_{2} \mathrm{Fe}_{4} \mathrm{O}_{11}$
}

\author{
G.K. Thompson and B.J. Evans \\ Department of Chemistry, University of Michigan, \\ Ann Arbor, MI 48109-1055, USA
}

The strong, and heretofore unexplained, dependence of the magnetic properties of the R-type hexaferrites $\mathrm{MX}_{2} \mathrm{Fe}_{4} \mathrm{O}_{11}$ on heat treatment has been investigated by means of ${ }^{57} \mathrm{Fe}$ and ${ }^{119} \mathrm{Sn}$ Mössbauer spectroscopy at $297 \mathrm{~K} .{ }^{57} \mathrm{Fe}$ Mössbauer spectra of samples of $\mathrm{BaTi}_{2} \mathrm{Fe}_{4} \mathrm{O}_{11}, \mathrm{BaSn}_{2} \mathrm{Fe}_{4} \mathrm{O}_{11}$, and $\mathrm{SrSn}_{2} \mathrm{Fe}_{4} \mathrm{O}_{11}$ annealed at several temperatures consist of three partially resolved quadrupole doublet patterns. The pattern with the very large quadrupole splitting, i.e. $1.3 \mathrm{~mm} \mathrm{~s}^{-1} \leq \Delta E_{\mathrm{Q}} \leq 1.7 \mathrm{~mm} \mathrm{~s}^{-1}$, is readily assigned to the trigonal bipyramidal site, and exhibits no dependence of its parameters, including the relative intensity, on heat treatment. The remaining two patterns are assigned to $\mathrm{Fe}^{3+}$ ions on octahedral sites, and exhibit relative intensities that are strongly dependent on heat treatment. The ${ }^{119} \mathrm{Sn}$ spectrum of $\mathrm{BaSn}_{2} \mathrm{Fe}_{4} \mathrm{O}_{11}$ is a broad, apparently single line that, with the exception of verifying the presence of tin as $\mathrm{Sn}^{4+}$, provides little insight into the details of the structure. The distributions of the cations over all the lattice sites have been deduced from the Mössbauer spectra and compared with the magnetic susceptibility data. It is concluded that the cation distributions of the Sn-containing phase are not strongly dependent on heat treatment, and the magnetic properties exhibit a similar insensitivity to heat treatment. The $\mathrm{Ti}$ analogs exhibit a strong dependence of cation distribution on heat treatment, which is reflected in widely varying magnetic ordering temperatures, a variation that is confirmed by the incipient magnetic hyperfine splitting despite the strong magnetic frustration in the R-type hexaferrites.

\section{Introduction}

Hexagonal ferrites with the magnetoplumbite structure-type, e.g. $\mathrm{MFe}_{12} \mathrm{O}_{19}$ $(\mathrm{M}=\mathrm{Pb}, \mathrm{Sr}, \mathrm{Ba})$, are of considerable commercial and technical importance as permanent magnetic materials, recording media, and as components in consumer electronics, microwave, and high-frequency devices. There is much, however, that is not understood regarding the relationship between their structure and magnetic and electronic properties. The prospects for advances in our understanding of these materials have been heightened by considering the magnetoplumbites to consist of two structural subunits: an " $\mathrm{S}$ ", or spinel block, with $\mathrm{S}=\mathrm{Fe}_{6} \mathrm{O}_{8}^{2+}$, and a hexagonal 
" $\mathrm{R}$ " block, with $\mathrm{R}=\mathrm{MFe}_{6} \mathrm{O}_{11}^{2-}$. Structure-property relationships for the spinel block have been extensively investigated, and are well understood, at least qualitatively. However, until recently, the $R$ subunit was not known as an isolated phase, and attempts to understand the properties of the magnetoplumbite hexaferrites in terms of the constituent subunits were not possible. The recent discovery of stable Rblock components has removed this impediment.

The R-type hexaferrites contain three crystallographic sites for the $\mathrm{Fe}^{3+}$ ions that are analogs of sites in the $\mathrm{R}$ subunit in $\mathrm{MFe}_{12} \mathrm{O}_{19}$; the trigonal bipyramidal $4 \mathrm{f}(1 / 2)$, the face-shared octahedral $4 \mathrm{e}$, and the edge-shared octahedral $6 \mathrm{~g}$ sites correspond to the $2 \mathrm{~b}, 4 \mathrm{f}_{2}$, and $12 \mathrm{k}$ sites, respectively, in $\mathrm{MFe}_{12} \mathrm{O}_{19}$. Although some of the R-type hexaferrites have been investigated by means of ${ }^{57} \mathrm{Fe}$ and ${ }^{119} \mathrm{Sn}$ Mössbauer spectroscopy [1-5], a definitive set of hyperfine interaction parameters is lacking, as are magnetic susceptibility data.

\section{Experimental}

Polycrystalline samples of $\mathrm{BaTi}_{2} \mathrm{Fe}_{4} \mathrm{O}_{11}, \mathrm{BaSn}_{2} \mathrm{Fe}_{4} \mathrm{O}_{11}$, and $\mathrm{SrSn}_{2} \mathrm{Fe}_{4} \mathrm{O}_{11}$ were prepared from the appropriate oxides and carbonates, using the solid-state synthesis described by Cadée et al. [6]. In addition, some samples were annealed for 7-14 days at 673,973 , and $1423 \mathrm{~K}$, and quenched in air. Transmission ${ }^{57} \mathrm{Fe}$ Mössbauer spectra were then obtained at $297 \mathrm{~K}$ for the three annealed compositions, and at $83 \mathrm{~K}$ for $\mathrm{BaTi}_{2} \mathrm{Fe}_{4} \mathrm{O}_{11}$ annealed at $1423 \mathrm{~K}$. ${ }^{119} \mathrm{Sn}$ spectra were also obtained at $297 \mathrm{~K}$ for $\mathrm{BaSn}_{2} \mathrm{Fe}_{4} \mathrm{O}_{11}$. The spectra were analyzed as described in detail in a previous report [7]. X-ray powder diffractometry was employed to establish that each sample was single-phase. Magnetization measurements were performed on powders by means of a SQUID magnetometer.

\section{Results and discussion}

${ }^{57} \mathrm{Fe}$ Mössbauer spectra at $297 \mathrm{~K}$ for $\mathrm{BaTi}_{2} \mathrm{Fe}_{4} \mathrm{O}_{11}, \mathrm{BaSn}_{2} \mathrm{Fe}_{4} \mathrm{O}_{11}$, and $\mathrm{SrSn}_{2} \mathrm{Fe}_{4} \mathrm{O}_{11}$ (fig. 1) can all be resolved into three quadrupole doublets. As with the 2b subspectrum in $\mathrm{MFe}_{12} \mathrm{O}_{19}$, the smaller isomer shift $\delta$ and unusually large quadrupole splitting $\Delta E_{\mathrm{Q}}$ clearly identify the trigonal bipyramidal $4 \mathrm{f}(1 / 2)$ subspectrum. Analysis of the relative intensities of the remaining doublets makes it possible to properly assign the $4 \mathrm{e}$ and $6 \mathrm{~g}$ sites to each. The hyperfine parameters resulting from fitting these spectra to three symmetric quadrupole doublets are listed in table 1 .

Analysis of the relative intensities of the doublets of the $297 \mathrm{~K}{ }^{57} \mathrm{Fe}$ spectra (table 1) indicates that the $4 \mathrm{f}(1 / 2)$ bipyramidal site in all three hexaferrites is occupied almost exclusively by $\mathrm{Fe}^{3+}$ ions. In the samples annealed at or above $1423 \mathrm{~K}, 63 \%$ of the $\mathrm{Ti}^{4+}$ ions and $70 \%$ of the $\mathrm{Sn}^{4+}$ ions in $\mathrm{BaX}_{2} \mathrm{Fe}_{4} \mathrm{O}_{11}$, and $72 \%$ of the $\mathrm{Sn}^{4+}$ ions in $\mathrm{SrSn}_{2} \mathrm{Fe}_{4} \mathrm{O}_{11}$ occupy the edge-sharing $6 \mathrm{~g}$ site, with correspondingly smaller fractions in the face-sharing $4 \mathrm{e}$ sites, in agreement with Pauling's rules [8]. For $\mathrm{BaX}_{2} \mathrm{Fe}_{4} \mathrm{O}_{11}$ 


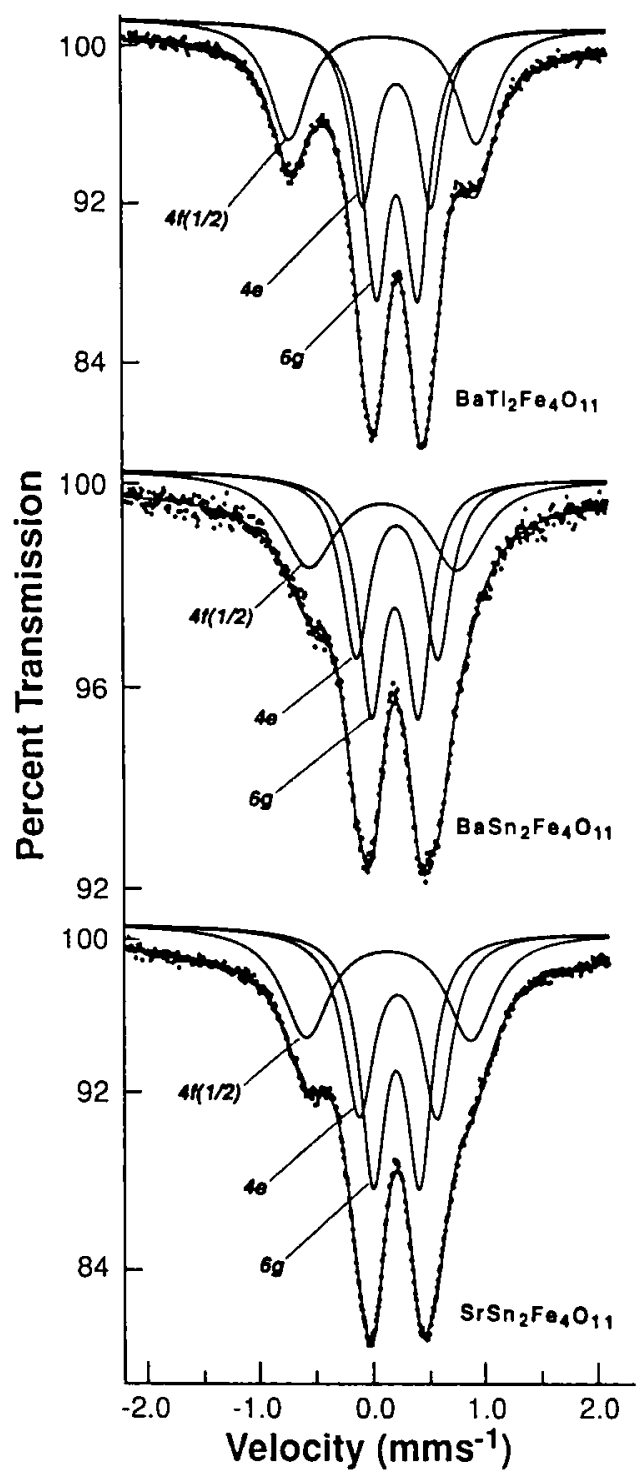

Fig. 1. $297 \mathrm{~K}{ }^{57} \mathrm{Fe}$ Mössbauer spectra of polycrystalline R-type hexaferrites annealed at $973 \mathrm{~K}$.

$(\mathrm{X}=\mathrm{Ti}, \mathrm{Sn})$ annealed at $973 \mathrm{~K}, 77 \%$ of the $\mathrm{Sn}^{4+}$ ions occupy the $6 \mathrm{~g}$ sites, but $72 \%$ of the $\mathrm{Ti}^{4+}$ ions reside in the electrostatically less-favored $4 \mathrm{e}$ face-sharing octahedra. The room temperature ${ }^{119} \mathrm{Sn}$ Mössbauer spectra of $\mathrm{BaSn}_{2} \mathrm{Fe}_{4} \mathrm{O}_{11}$ annealed at 973 and $1423 \mathrm{~K}$ showed only one unresolved doublet with a quadrupole splitting 
Table 1

$297 \mathrm{~K}{ }^{57} \mathrm{Fe}$ Mössbauer parameters and $\mathrm{X}^{4+}$ ion distribution for different heat treatment of $\mathrm{MX}_{2} \mathrm{Fe}_{4} \mathrm{O}_{11}$.

\begin{tabular}{|c|c|c|c|c|c|c|c|c|c|}
\hline \multirow[b]{2}{*}{ Sample } & \multicolumn{3}{|c|}{$4 f(1 / 2)$ site } & \multicolumn{3}{|c|}{$4 e$ site } & \multicolumn{3}{|c|}{$6 \mathrm{~g}$ site } \\
\hline & $\begin{array}{c}\Delta E_{\mathrm{Q}} \\
\left(\mathrm{mm} \mathrm{s}^{-1}\right)\end{array}$ & $\begin{array}{c}\delta^{\mathrm{a})} \\
\left(\mathrm{mm} \mathrm{s}^{-1}\right)\end{array}$ & $\begin{array}{c}\% \text { of } X^{4+} \\
\text { present }\end{array}$ & $\begin{array}{c}\Delta E_{\mathrm{Q}} \\
\left(\mathrm{mm} \mathrm{s}^{-1}\right)\end{array}$ & $\begin{array}{c}\delta \\
\left(\mathrm{mm} \mathrm{s}^{-1}\right)\end{array}$ & $\begin{array}{c}\% \text { of } \mathrm{X}^{4+} \\
\text { present }\end{array}$ & $\begin{array}{c}\Delta E_{\mathrm{Q}} \\
\left(\mathrm{mm} \mathrm{s}^{-1}\right)\end{array}$ & $\begin{array}{c}\delta \\
\left(\mathrm{mm} \mathrm{s}^{-1}\right)\end{array}$ & $\begin{array}{r}\% \text { of } X^{4+} \\
\text { present }\end{array}$ \\
\hline $\begin{array}{c}\mathrm{BaTi}_{2} \mathrm{Fe}_{4} \mathrm{O}_{11} \\
(973 \mathrm{~K})\end{array}$ & $1.70(0)$ & $0.26(0)$ & 0 & $0.67(1)$ & $0.37(0)$ & 72 & $0.42(1)$ & $0.38(0)$ & 28 \\
\hline $\begin{array}{c}\mathrm{BaTi}_{2} \mathrm{Fe}_{4} \mathrm{O}_{11} \\
(1423 \mathrm{~K})\end{array}$ & $1.71(0)$ & $0.26(0)$ & 0 & $0.62(0)$ & $0.38(1)$ & 37 & $0.38(0)$ & $0.38(0)$ & 63 \\
\hline $\begin{array}{c}\mathrm{BaSn}_{2} \mathrm{Fe}_{4} \mathrm{O}_{11} \\
(973 \mathrm{~K})\end{array}$ & $1.33(1)$ & $0.26(0)$ & 0 & $0.73(0)$ & $0.37) 0)$ & 23 & $0.42(1)$ & $0.35(0)$ & 77 \\
\hline $\begin{array}{c}\mathrm{BaSn}_{2} \mathrm{Fe}_{4} \mathrm{O}_{11} \\
(1423 \mathrm{~K})\end{array}$ & $1.34(1)$ & $0.25(0)$ & 0 & $0.74(1)$ & $0.37(0)$ & 30 & $0.43(0)$ & $0.35(0)$ & 70 \\
\hline $\begin{array}{c}\mathrm{SrSn}_{2} \mathrm{Fe}_{4} \mathrm{O}_{11} \\
(1573 \mathrm{~K})\end{array}$ & $1.50(1)$ & $0.28(0)$ & 0 & $0.71(1)$ & $0.36(0)$ & 28 & $0.42(1)$ & $0.36(1)$ & 72 \\
\hline
\end{tabular}



of $0.44 \mathrm{~mm} \mathrm{~s}^{-1}$ and $0.47 \mathrm{~mm} \mathrm{~s}^{-1}$, respectively, and in both cases, an isomer shift (relative to $\mathrm{SnO}_{2}$ ) of $0.14 \mathrm{~mm} \mathrm{~s}^{-1}$. These data clearly indicate the presence of $\mathrm{Sn}^{4+}$, and are in good agreement with previously reported spectra [3].

The mass susceptibility data for $\mathrm{BaTi}_{2} \mathrm{Fe}_{4} \mathrm{O}_{11}$ and $\mathrm{BaSn}_{2} \mathrm{Fe}_{4} \mathrm{O}_{11}$ annealed at various temperatures (fig. 2) demonstrate that the magnetic behavior of the tin ferrite is quite complex and distinct from its $\mathrm{Ti}$ analog. These data confirm earlier reports that $\mathrm{BaTi}_{2} \mathrm{Fe}_{4} \mathrm{O}_{11}$ behaves like a typical ferrimagnet with a Curie temperature that varies with the thermal history of the material $[1,6]$. However, there are quantitative differences between the results of this investigation and those reported earlier. For example, an earlier investigation reports $T_{\mathrm{C}}$ values of 184 and $213 \mathrm{~K}$ for $\mathrm{BaTi}_{2} \mathrm{Fe}_{4} \mathrm{O}_{11}$ annealed at 1273 and $1573 \mathrm{~K}$, respectively [1]. The data obtained from this investigation place $T_{\mathrm{C}}$ at $80 \mathrm{~K}$ for $\mathrm{BaTi}_{2} \mathrm{Fe}_{4} \mathrm{O}_{11}$ annealed at $973 \mathrm{~K}$, and at $90 \mathrm{~K}$ for the sample annealed at $1423 \mathrm{~K}$. Furthermore, these lower $T_{\mathrm{C}}$ values are in agreement with the Mössbauer spectrum obtained at $83 \mathrm{~K}$ (fig. 3), which shows only the beginning of magnetic ordering in the sample annealed at $1423 \mathrm{~K}$. This magnetically split subspectrum is of low intensity, and is overlapped by an intense, broad central peak; the corresponding hyperfine magnetic field has been estimated to be $475 \mathrm{kOe}$. The presence of the large paramagnetic peak overlapping the magnetic sextet is consistent with spectra of magnetically frustrated materials, of which of R-type hexaferrite class is an example, near the magnetic transition temperature $[1,4]$. 

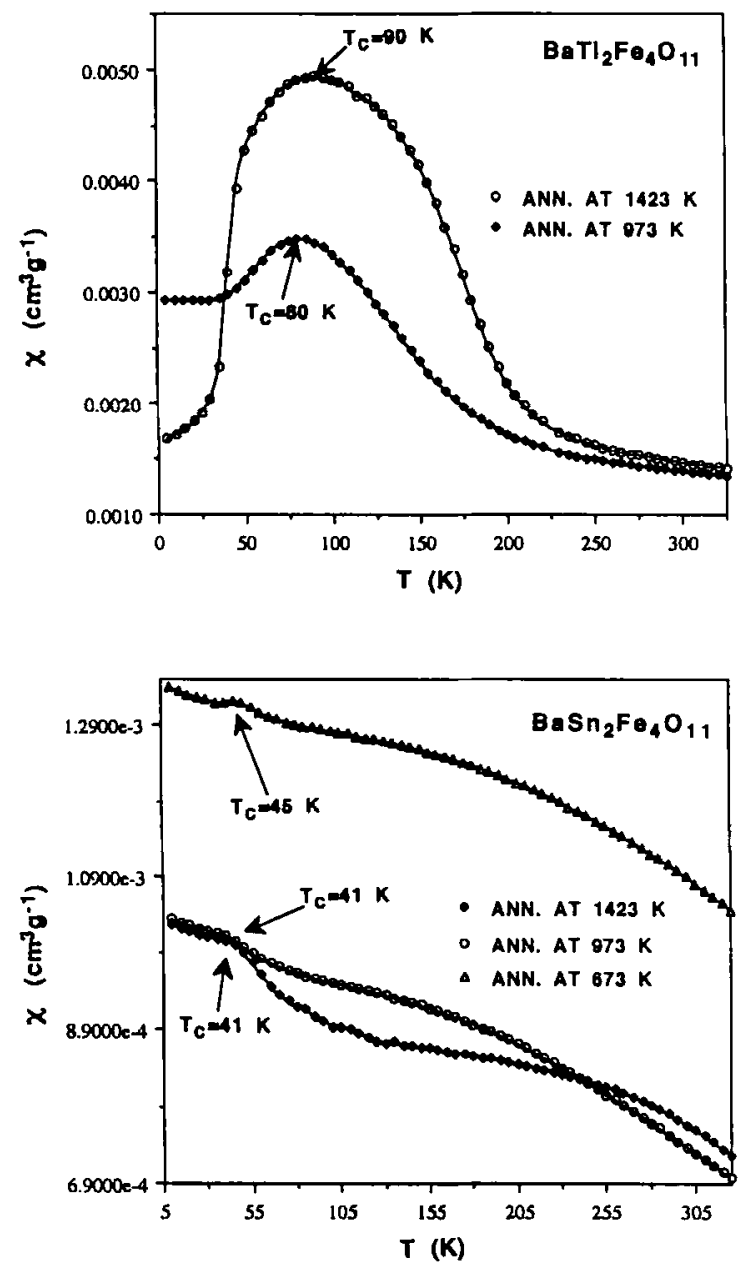

Fig. 2. (a) Magnetic susceptibility versus temperature plot for polycrystalline $\mathrm{BaTi}_{2} \mathrm{Fe}_{4} \mathrm{O}_{11}$ annealed at 973 and $1423 \mathrm{~K}$. (b) Magnetic susceptibility versus temperature plot for polycrystalline $\mathrm{BaSn}_{2} \mathrm{Fe}_{4} \mathrm{O}_{11}$ annealed at 673,973 , and $1423 \mathrm{~K}$.

\section{Conclusion}

The dependence of the magnetic behavior of $\mathrm{BaX}_{2} \mathrm{Fe}_{4} \mathrm{O}_{11}$ on thermal history may now be related directly to the temperature-dependent cation distributions on the octahedral sites. In $\mathrm{BaSn}_{2} \mathrm{Fe}_{4} \mathrm{O}_{11}$, the cation distribution is virtually the same for annealings at 973 and $1423 \mathrm{~K}$, leading to the same $T_{C}$ of $41 \mathrm{~K}$. Furthermore, the presence of the $\mathrm{Sn}^{4+}$ ions has resulted in a rather complicated set of magnetic exchange interactions, as is evidenced by the lack of prominent magnetic transition points in the $\chi$ versus $T$ curves. This unusual behavior is due to the high degree of frustration of the magnetic sublattices. 


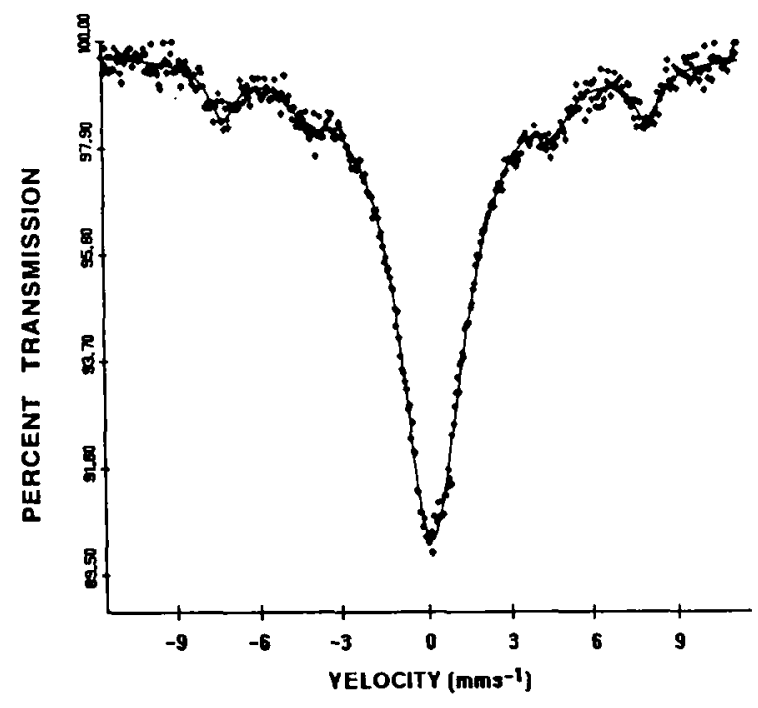

Fig. 3. $83 \mathrm{~K}{ }^{57} \mathrm{Fe}$ Mössbauer spectrum of polycrystalline $\mathrm{BaTi}_{2} \mathrm{Fe}_{4} \mathrm{O}_{11}$ annealed at $1423 \mathrm{~K}$.

In the case of the $\mathrm{Ti}$ analog, however, the large difference in the octahdral cation distribution leads to a readily measurable difference in $T_{\mathrm{C}}$ for samples with different thermal histories. The rather ordinary appearance of the $\chi$ versus $T$ curves for $\mathrm{BaTi}_{2} \mathrm{Fe}_{4} \mathrm{O}_{11}$ suggests that magnetic frustration is considerably reduced below that of its $\mathrm{Sn}$ analog.

The Mössbauer spectra and susceptibility data for $\mathrm{BaTi}_{2} \mathrm{Fe}_{4} \mathrm{O}_{11}, \mathrm{BaSn}_{2} \mathrm{Fe}_{4} \mathrm{O}_{11}$, and $\mathrm{SrSn}_{2} \mathrm{Fe}_{4} \mathrm{O}_{11}$ indicate that the R-type hexaferrites have more complex magnetic properties than were previously supposed. The dependence of the magnetic properties on thermal history is related to the temperature dependence of the cation distributions on the ocahedral sites. Despite the complexities of the crystal- and magnetochemistry of the R-type hexaferrites, additional investigations of their composition, structure, and properties may yet allow a more complete understanding of structure/property relationships in magnetoplumbite-type hexaferrites.

\section{References}

[1] E. Kneller, M. Velicescu and F. Haberey, J. Magn. Magn. Mater. 7(1978)49.

[2] X. Obradors, A. Collomb, J. Pannetier, A. Isalgué, J. Tejada and J.C. Joubert, Mater. Res. Bull. 18(1983)1543.

[3] T. Birchall and C. Hallett, Solid State Commun. 56(1985)77.

[4] K. Iwauchi and Y. Ikeda, J. Magn. Magn. Mater. 59(1986)73.

[5] K. Iwauchi, Y. Ikeda, N. Koizumi and Y. Bando, J. Magn. Magn. Mater. 31-34(1983)1384.

[6] M.C. Cadée and D.J.W. Ijdo, J. Solid State Chem. 52(1984)302.

[7] B.J. Evans, F. Grandjean, A.P. Lilot, R.H. Vogen and A. Gérard, J. Magn. Magn. Mater. 67(1987)123.

[8] L. Pauling, The Nature of the Chemical Bond (Cornell University Press, Ithaca, 1960). 